\title{
Utilization of blast furnace flue dust while modifying gypsum binders with carbon nanostructures
}

\author{
Grigory Yakovlev ${ }^{\mathrm{a}}$, Vadim Khozin ${ }^{\mathrm{b}}$, Irina Polyanskikh ${ }^{\mathrm{a}}$, Jadvyga Keriene ${ }^{\mathrm{c}}$, \\ Anastasiia Gordina ${ }^{\mathrm{a}}$, Tatyana Petrova ${ }^{\mathrm{d}}$ \\ aFaculty of Civil Engineering,, Izhevsk State Technical University, Studencheskaya St., 7, Izhevsk 426069, Russia, \\ bConstruction Engineering Faculty, Kazan State University of Architecture and Civil Engineering, Zelenaya St., 1, Kazan 420000, Russia \\ cFaculty of Fundamental Sciences, Vilnius Gediminas Technical University, Sauletekio al., 11, Vilnius 10223, Lithuania \\ dFaculty of Civil Engineering, Petersburg State Transport University, Moscow Avenue, 9, St. Petersburg 190031, Russia
}

\begin{abstract}
For improvement of physico-mechanical properties of plaster materials the industrial waste - metallurgical dust formed by manufacture of steel, was used. Modification of gypsum binder by adding metallurgical dust in quantity $0.5 \%$ from the weight the binder caused the significant change in microstructure of the gypsum stone, this led to an increase in compressive strength by $80 \%$ and to increase of softening coefficient up to 0.85 . Such parameters are provided due to formation of crystals of the gypsum protected by an environment of amorphous structure, less soluble, than the not protected crystals of gypsum, preventing destruction crystals of gypsum and water limiting access to crystals of gypsum matrix. For achievement synergetic effect with metallurgical dust dispersions multi walled carbon nanotubes (MWCNTs) were added. MWCNTs act as the centers of crystallization on which surface is going the formation of the ordered dense structure to block packing crystals. The presence in metallurgical dust calcium hydroxide leads to formation of amorphous phase on surface of crystals of gypsum. The developed plaster composition modified by the combined additive according to its properties is similar to waterproof materials. Recycling of metallurgical dust using it as the additive modifying gypsum binder, will improve the ecological conditions in area of an arrangement of the steel production metallurgical complexes.
\end{abstract}

Keywords: gypsum binder; multi-walled carbon nanotubes; crystallization centers; metallurgical dust; microstructure.

\section{Introduction}

The properties of gypsum materials are largely determined by the state and structure of the matrix. Reducing many disadvantages of gypsum binders and products can be the result of creating the composites with the additives that affect the flow of hydration and formation of the structure of gypsum binders [1-2]: varying the size and morphology of crystals, the state of the interface and the total porosity.

Low water resistance and high creep of gypsum materials are known to be predetermined by the crystal structure and the increased solubility of calcium sulfate dihydrate. As it can be seen in Fig. 1, under the influence of environmental changes the morphology of primary gypsum crystals changes and the defective structure is formed.

Therefore, the gypsum crystals formed during gypsum hardening should be covered with protective shell which is less soluble than gypsum and prevents the destruction of gypsum crystals limiting the water penetration into the gypsum crystals.

There are various ways to improve the water resistance of gypsum binders by adding additives which are industrial waste. Thus, using chromium-alumina catalyst [3-4], waste of petrochemical production, leads to the formation of dense fine-crystalline structure of anhydrite matrix with finely dispersed amorphous new formations and improves the physical and mechanical properties of the binder. Using aluminous mixture [5] (smelter slag) leads to the formation of amorphous structures on the surface of gypsum crystals covering the surface of crystal hydrates and leading to the increased water resistance of gypsum matrix.

Corresponding author: Grigory Yakovlev. E-mail address: gyakov@istu.ru

http://dx.doi.org/10.3846/enviro.2014.025

(C) 2014 The Authors. Published by VGTU Press. This is an open-access article distributed under the terms of the Creative Commons Attribution License, which permits unrestricted use, distribution, and reproduction in any medium, provided the original author and source are credited. 


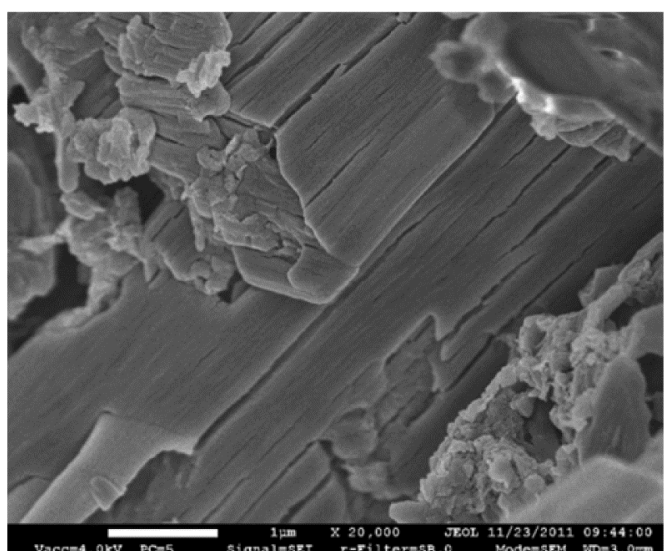

(a)

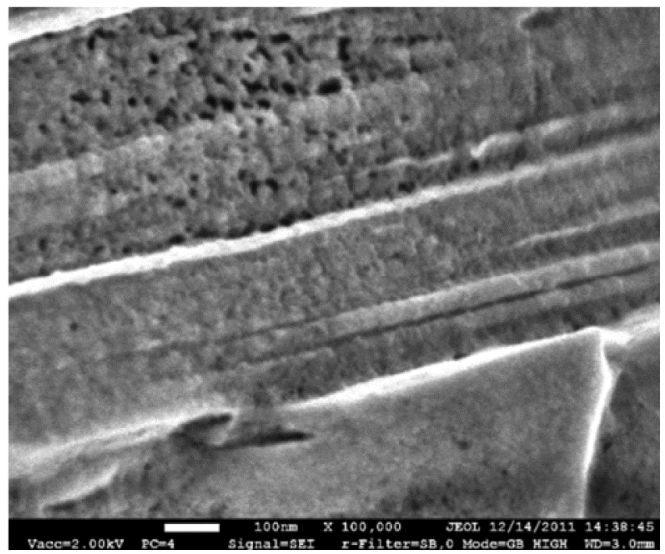

(b)

Fig. 1. Defective structure of gypsum formed under the environmental influence:

(a) - destruction of gypsum crystals as a result of removing interlayer water, (b) - interlayer erosion of lamellar gypsum

A number of researchers [6-8] offered some water-resistant gypsum compositions using the wastes of metallurgical industry, i.e. ground granulated blast-furnace slag, lime and active mineral additives. Also a complex hydraulic additive [9] containing ceramsite dust, ground blast furnace slag, lime and superplasticizer was offered; its adding provides the formation of a dense, strong and water-resistant structure of artificial stone.

At the same time chemical composition and high dispersion of metallurgical dust causes the perspective of it is use as raw material, especially as modifying additive, in the production of construction materials, including gypsum. Researches of the properties and structure of gypsum rock with metallurgical dust [10-11] have shown the effectiveness of this modifier that increases the technical properties of the binder.

Additives of nano-sized particles have high surface energy and chemical activity as well as stronger influence on the structure of the boundary layers of mineral matrices $[12-13,16]$. Adding carbon nanotubes dispersions to gypsum binders leads to the increase of the strength characteristics and the formation of strong and dense structure [13].

There are some ways to protect the gypsum structure from aggressive environment attack - the use of carbon nanotubes in combination with ultra-dispersed additives which leads to deeper changes in the structure of hardened gypsum [14]. Modifying binding matrices with multi-walled carbon nanotubes dispersions (MWCNTs) improves the physical and mechanical characteristics of gypsum composites due to the structuring of new formations whose morphology depends primarily on the degree of the uniform distribution of carbon nanotubes in the binder matrix.

Regardless numerous studies describing the structure and properties of gypsum matrices modified with carbon nanotubes, the mechanism of their influence has not been established yet.

The aim of this work - utilization of metallurgical dust while modifying gypsum binders with carbon nanostructures.

\section{Materials and methods}

Gypsum of the grade G-4 produced by LLC "Prikamskaya gypsum company" (Perm) is used as a binder, corresponding to [19].

Metallurgical (blast furnace flue) dust appearing in the steel production was used as ultra-dispersed additive. The dispersion analysis of the additive showed that the average size of particles is 20-30 microns. X-ray phase analysis of metallurgical dust showed that the highest intensity peaks on the X-ray correspond to iron (II, III) oxide and calcium hydroxide $\mathrm{Ca}(\mathrm{OH})_{2}$ which indicates their significant content in the additive [14].

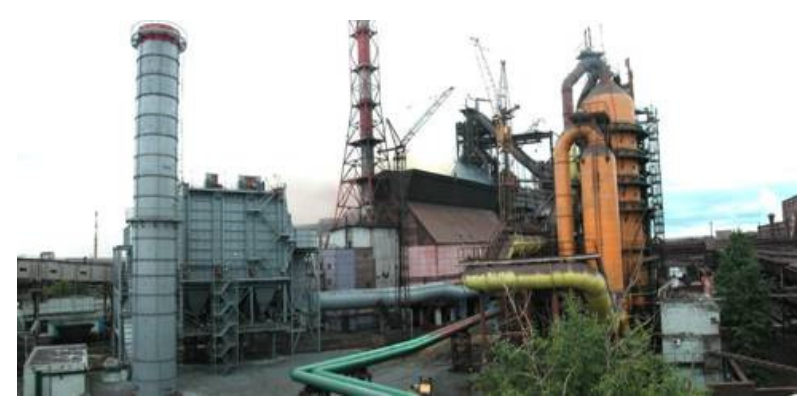

(a)

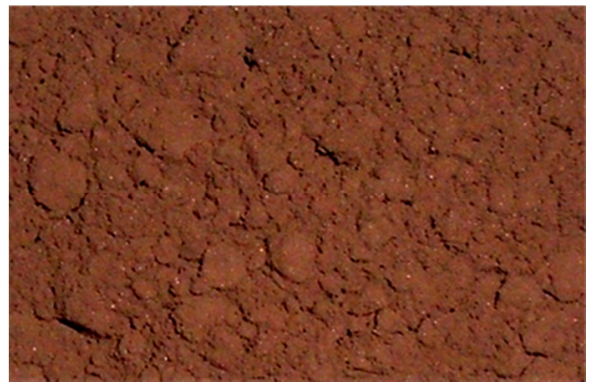

(b)

Fig. 2. Installation for the picking of metallurgical dust in the plant OAO "Tulachermet" [20] (a); (b) - photo of the metallurgical dust 
On the metallurgical dust amount accumulating in the metallurgical process can be judged according to metallurgical plant OAO "Tulachermet" data corresponding to 98,2 thousand tons in 2005.

An important issue to consider when using modifying additives based on MWCNTs is their thorough dispersion in the aqueous medium with surfactant additive. As a source of MWCNTs the Graphistrength ${ }^{\mathrm{TM}}$ CW2-45 produced by company "Arkema" (France) was used. Graphistrength ${ }^{\mathrm{TM}} \mathrm{CW} 2-45$ is provided in the form of pellets having composition (in mass \%): MWCNTs 45, carboxymethyl cellulose (surfactant) 55. The outer diameter of MWCNTs varies in range 10-15 nm, length 1-5 $\mu \mathrm{m}$. The preparation of dispersion was performed in accordance with the instructions of "Arkema", i.e. a Graphistrength ${ }^{\mathrm{TM}} \mathrm{CW} 2-45$ pellets were immersed in hot $\left(70-90^{\circ} \mathrm{C}\right)$ water for $15 \mathrm{~min}$ and then dispersed in high-speed mixer for 2 hours. For estimation of quality of disintegration of MWCNTs in the prepared dispersion its analysis using CILAS 1090 Liquid laser analyzer was conducted. The results of analysis showed the presence of particles with an average size of $230 \mathrm{~nm}$ in the aqueous dispersion (except the particles in the micrometer range) occupying $20 \%$ of the total volume. The dispersions of MWCNTs showed their required stability within 7 days after preparation.

Standard steel molds with sizes $40 \times 40 \times 160 \mathrm{~mm}$ have been used to obtain the gypsum samples. The samples have been kept in the molds for 20-30 minutes with further mechanical durability tests. The samples have been stored at $\mathrm{T}=20^{\circ} \mathrm{C}$ for 7, 14 and 28 days under normal humidity.

Table 1. Quantitative composition of gypsum specimens

\begin{tabular}{|c|c|c|c|c|}
\hline $7^{\text {Sample }} \begin{array}{r}\text { Sampositions } \\
\text { compons }\end{array}$ & Reference sample & $\begin{array}{l}\text { Sample with ultradisperse } \\
\text { additive }\end{array}$ & $\begin{array}{l}\text { Sample with } \\
\text { nanodisperse additive }\end{array}$ & $\begin{array}{l}\text { Sample with nano- and } \\
\text { ultradisperse additives }\end{array}$ \\
\hline Components & & & & \\
\hline Gypsum, \% & 100 & 100 & 100 & 100 \\
\hline Metallurgical dust, $\%$ & - & $0.1 ; 0.5 ; 1 ; 3$ & - & $0.2 ; 0.4 ; 0.6$ \\
\hline Carbon nanotubes, $\%$ & - & - & $0.01 ; 0.005 ; 0.001$ & 0.005 \\
\hline Water-gypsum ratio, $\%$ & 60 & 60 & 60 & 60 \\
\hline
\end{tabular}

The strength tests of the samples have been carried out on hydraulic press PGM-100 with the allowed load $100 \mathrm{kN}$ and loading speed $0.5 \mathrm{MPa} / \mathrm{s}$ in accordance with the standard requirements [19]. The average values calculated by the results of three successful measurements have been taken as the final test results.

The sample microstructure has been investigated with the help of microscope JSM $7500 \mathrm{~F}$ produced by JEOL with the accelerating voltage $4 \mathrm{kV}$. The X-ray phase analysis has been carried out on diffractometer DRON-2. Cobalt has been applied as an anti-cathode.

\section{Results and discussion}

The results of gypsum matrix microstructure investigation (Fig. 3) show that the use of additives resulted the change in gypsum matrix structure. It is clearly seen by comparing Fig.2a and Fig. 2b. Carbon nanostructures act as crystallizing nuclei on whose surface the ordered dense structure with block crystal density is formed (Fig. 2b).
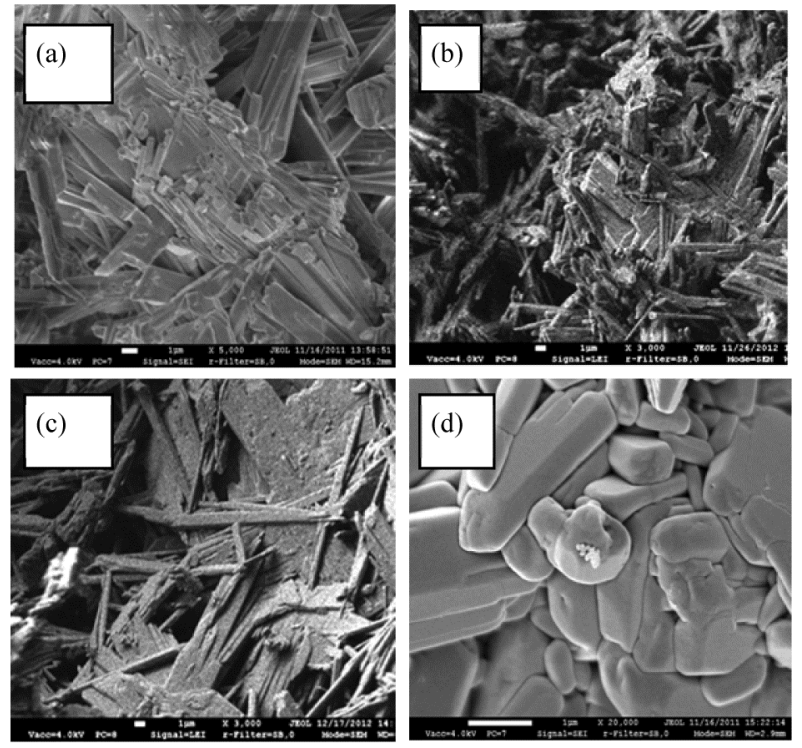

Fig. 3. Gypsum matrix microstructure: (a) - without additives; (b) - with carbon nanotubes;

(c) - with metallurgical dust; (d) - modified with metallurgical dust $(0.4 \%)$ and multi-walled carbon nanotubes dispersion $(0.005 \%)$ 
The presence of calcium hydroxide in blast furnace flue dust causes the formation of amorphous phase on the surface of gypsum crystals. For example, in study [18], the authors created the conditions for the formation of amorphous coatings of gypsum crystal hydrates blocking the direct water exposure on the structure of gypsum binding matrix due to the formation of hydrated calcium silicates.

The analysis of the results of mechanical tests (Fig. 4) showed that adding to up to $0.001 \%$ of MWCNTs to gypsum binding matrix improves its compressive strength, however, when the concentration is being increased further, the mechanical strength of gypsum binding matrix is gradually decreased. Carbon nanotubes having high surface energy and being the crystallizing nucleus accelerate the crystallization of new formations. Nevertheless, when the optimum value of nanotubes being exceeded (achieves more than $0.001 \%$ ), there is a gradual drop in the strength due to the shortage of gypsum binder for the highly-developed surface of carbon nanotubes.

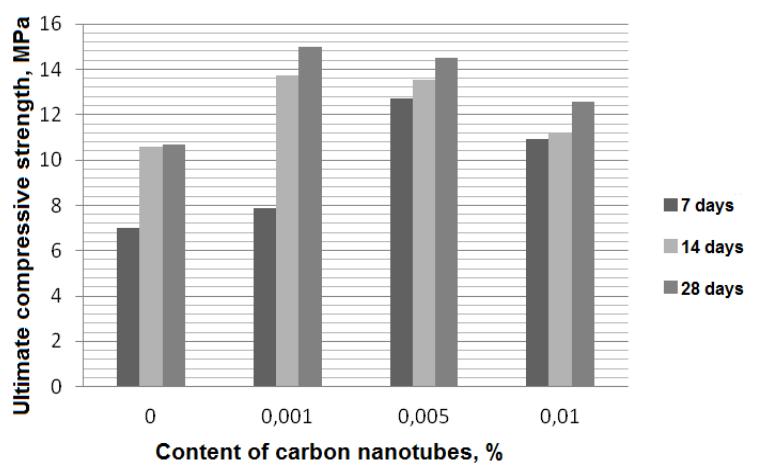

Fig. 4. Strength of gypsum matrix with multi-walled carbon nanotubes added

The analysis of the results of mechanical tests showed (Fig. 5) that the strength increase of $80 \%$ was achieved when the metallurgical dust additive content was $0.4 \%$, but at the further increase of concentration the mechanical characteristics of gypsum stone gradually decreased.

Previously, it was found [14] that the combined introduction of ultra- and nanodispersed modifiers with significant surface energy contributes to synergetic effect resulting in drastic changes in the structure of gypsum matrix.

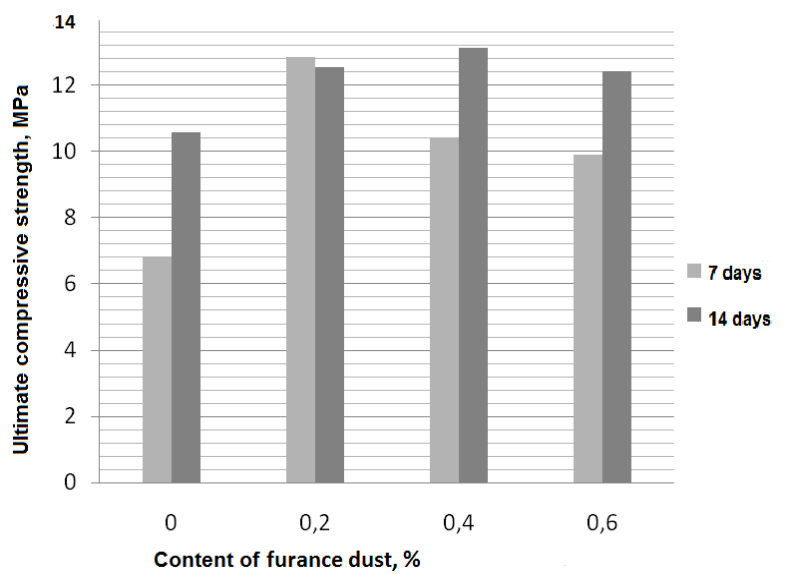

Fig. 5. Strength of gypsum matrix with multi-walled carbon nanotubes $(0.005 \%)$ and furnace dust

Additives at a certain concentration ( $0.4 \%$ metallurgical dust and $0.005 \%$ MWCNTs) act as active centers on which surfaces crystalline hydrates of calcium sulfate dihydrate occur forming the film structure of the gypsum matrix with the increased density and strength in the gaps between the particles, i.e. a significant increase in the strength characteristics is associated with the synergetic effect which occurs when adding metallurgical dust and carbon nanotubes with high surface energy leading to the transfer of matrix from the volumetric state in film. As a result the physical and mechanical properties of the gypsum matrix increase at the optimal content of $0.005 \%$ of MWCNTs and $0.4 \%$ of blast furnace flue dust by the mass of the gypsum binder.

Probably the amorphous component on the gypsum crystals surface reduces the "wedging" effect of interlayer water which is considered to reduce the water resistance of gypsum materials (Table 2).

The presented data show that the water absorption of the studied compositions ranges from $25.3-30.7 \%$ which is slightly higher than a similar characteristic of the control specimen. The softening coefficient of the gypsum matrix with $0.5 \%$ of metallurgical dust significantly increases from 0.4 to 0.85 . 
Table 2. Water resistance of gypsum compositions

\begin{tabular}{llll}
\hline № & Content if furnace dust, \% & $\begin{array}{l}\text { Water absorption, } \% \\
\text { After 4 hours }\end{array}$ & Softening coefficient \\
\hline 1 & 0 & 25.3 & 0.4 \\
\hline 2 & 0.1 & 26.2 & 0.8 \\
\hline 3 & 0.5 & 26.2 & 0.85 \\
\hline 4 & 1 & 27.4 & 0.8 \\
\hline 5 & 3 & 30.7 & 0.64 \\
\hline
\end{tabular}

\section{Conclusion}

The investigation results showed that the modification of gypsum binder using combined additive of metallurgical dust and MWCNTs in quantities respectively $0.4 \%$ and $0.005 \%$, calculated from the weight of binder, causes an increase in compressive strength by $80 \%$. The plaster, modified by metallurgical dust in quantity of $0.5 \%$, according to its properties is similar to waterproof materials. These results suggest that the waste of metallurgical complexes - metallurgical dust - can be used with the aim to improve the compressive strength and water resistance of gypsum-based materials.

The utilization of metallurgical dust as an additive to modify plasters will improve the ecological situation in the areas of metallurgical complexes producing steel.

\section{References}

[1] Ferronskaya, A. V. 2004. Gypsum materials and products (production and application). Guide. Moscow: ASB publishing house. $488 \mathrm{~S}$.

[2] Belov, V. V.; Buryanov, A. F.; Yakovlev, G. I. ; Petropavlovskaya, V. B.; Fisher, H.-B.; Maeva, I. S.; Novichenkova, T. B. 2012. Modification of structure and properties of construction materials based on calcium sulfate: monograph. Moscow: De Nova publishing house. $196 \mathrm{~S}$.

[3] Tokarev, Yu.; Yakovlev, G. I. 2010. Effect of alumina dispered fillers on the properties and structure of anhydrite binder, KazGASU Izvestiya 1(13) : $357-362$

[4] Tokarev, Yu.; Yakovlev, G. I. 2009. Use of Technogenic Alumo-chrome Catalyst in Anhedrite Compositions, Pollack Periodica 3: $79-85$. http://dx.doi.org/10.1556/Pollack.4.2009.3.7

[5] Tokarev, Yu.; Yakovlev, G. I. 2010. Activation of hardening anhydrite composition with superdispersed agents, in Proceedings The 10 $0^{\text {th }}$ International conference "Moder building materials, Structures and Techniques", Lithuani, 2010. Vilnius, 295-299.

[6] Budnikov, P. P. 1943. Gypsum, its study and application. Moscow: Gosstroyizdat. 373 S.

[7] Bulychev, G. G. 1952. Mixed gypsums. Production and application in construction. Moscow: Gosstroyizdat. 134 S.

[8] Volzhenskiy, A. V.; Rogovoi, V. I.; Stambulko, V. I. 1960. Gypsum cement and gypsum slag binders. Moscow: State publishing house of literature on construction, architecture and construction materials. $168 \mathrm{~S}$.

[9] Khaliullin, M. I.; Gayfullin, A. R. 2010 Bond plasters based on composition gypsum binder with increased water resistance of components, KazGASU Izvestiya 2: 292-296.

[10] Gordina, A. F.; Tokarev, Y. V.; Pervushin, G. N.; Buryanov, A. F. 2012. Calsium sulfate-based compositions modified with superdiapersed additives, in Сборник трудов 18. Internationale Baustofftagung, Weimar, Germany, 12-15 september 2012. Weimar: Band 1, $0733-0740$.

[11] Khazeev, D. R.; Gordina, A. F.; Maeva, I. S.; Yakovlev, G. I; Buryanov, A. F. 2011. Influence of technogenic dispersed waste on structure and properties of composites based on calcium sulfate, Construction materials 6: 6-7.

[12] Yakovlev, G. I.; Pervushin, G. N.; Maeva, I. S.; Korzhenko, A.; Buryanov, A. F.; Machulaytis, R. 2010. Modification of anhydrite compositions with multi-walled carbon nanotubes, Construction materials 7: 25-27

[13] Yakovlev, G. I.; Pervushin, G. N.; Maeva, I. S.; Kerene, J.; Pudov, I. A.; Shajbadullina, A. V.; Korzhenko, A.; Bur'janov, A. F.; Sen'kov, S. A.; 2013. Modification of Construction Materials with Multi-Walled Carbon Nanotubes, Procedia Engineering Modern Building Materials, Structures and Techniques 57: 407-413.

[14] Gordina, A. F.; Tokarev, Ju. V.; Jakovlev, G. I.; Kerene, Ja.; Sychugov, S. V.; Mohamed, A. E. S. 2013. Evaluation of the Influence of Ultradisperse Dust and Carbon Nanostructures on the Structure and Properties of Gypsum Binders, Procedia Engineering Modern Building Materials, Structures and Techniques 57: 334-342.

[15] Korzhenko, A.; Havel, M.; Gaillard, P.; Yakovlev, G. I.; Pervuchin, G. N.; Oreshkin, D. V. 2012. Procede D'introduction de nanocharges carbonees dans un inorganique durcissable. Patent № 2969 143. C 04 B 16/12 (2012.01), C 04 B 28/00. Bulletin 12/25 pub. 22.06.12.

[16] Yakovlev, G. I.; Maeva, I. S.; Burjanov, A. F.; Fisher, H.-B.; Chasejev, D. R.; Isrjadnova, O. V. 2012. Modellierung der Struktur einer mit Kohlenstoffnanasystemen modifizierten Anhydritmatrix, in Сборник трудов 18. Internationale Baustofftagung,, Weimar, Germany, 12-15 september 2012. Weimar: Band 1, 0970-0979.

[17] Maeva, I. S.; Jakovlev, G. I.; Pervuschin, G. N.; Fischer, H.-B.; Korzhenko, A.; Burjanov, A.F. 2011. Einfluss von mehrschichtigen Kohlenstoffnanoroeren auf die Struktur und Eigenschaften der Anhydritbindemittel., in Weimarer Gipstagung: Gips (nicht) nur im Bauwesen Weimar, Germany,2011. Weimar: 423-429.

[18] Gaiducis, S.; Zvironaite, Ja;, Maciulaitis, R.; Jakovlev, G. 2011. Resistance of Phosphogypsum Cement Pozzolanic Compositions against the Influence of Water. Materials Science (Medziagotyra), , Procedia Engineering Modern Building Materials, Structures and Techniques 3: 308-313.

[19] GOST 23789-79 (state standard). Gypsum binders. Test methods. - Moscow: Publishers of standards, 1987, p. 8.

[20] Kurunov, I. F.; Titov, V. N.; Bolshakova, O. G. 2007. Analysis of effective ways to recycle the dispersed iron-bearing metallurgical wastes International conference "Advances in metallurgical processes and materials», 27-30 May 2007, Ukraine, Dnipropetrovsk, 372-377. 